\title{
Effects of Sibutramine on the Treatment of Obesity in Patients with Arterial Hypertension
}

\author{
Alessandra Nunes Faria, Fernando Flexa Ribeiro Filho, Daniel Diniz G. Lerário, Nárcia Kohlmann, \\ Sandra Roberta Gouvea Ferreira, Maria Teresa Zanella
}

São Paulo, SP

Objective - To assess the effects of weight reduction with $10 \mathrm{mg}$ of sibutramine or placebo on blood pressure during 24 hours (ambulatory blood pressure monitoring), on left ventricular mass, and on antihypertensive therapy in 86 obese and hypertensive patients for 6 months.

Methods - The patients underwent echocardiography, ambulatory blood pressure monitoring, and measurement of the levels of hepatic enzymes prior to and after treatment with sibutramine or placebo.

Results - The group using sibutramine had a greater weight loss than that using placebo $(6.7 \%$ versus $2.5 \%$; $p<0.001)$, an increase in heart rate (78.3 \pm 7.3 to $82 \pm 7.9$ bpm; $p=0.02)$, and a reduction in the left ventricular mass/ height index (105 29.3 versus $96.6 \pm 28.58 \mathrm{~g} / \mathrm{m}$; $p=0.002$ ). Both groups showed similar increases in the levels of alkaline phosphatase and comparable adjustments in antihypertensive therapy; blood pressure, however, did not change.

Conclusion - The use of sibutramine caused weight loss and a reduction in left ventricular mass in obese and hypertensive patients with no interference with blood pressure or with antihypertensive therapy.

Key words: sibutramine, obesity, arterial hypertension

Hospital do Rim e Hipertensão - Universidade Federal de São Paulo Mailing address: Alessandra Nunes Faria - Fundação Oswaldo Ramos - Rua Borges Lagoa, 960 - 04038-002 - São Paulo, SP, Brazil - E-mail: ale_faria@uol.com.br English version by Stela Maris C. e Gandour
The prevalence of obesity and its associated morbidities has increased in several countries worldwide, including Brazil ${ }^{1,2}$. The increase in body mass index has proved to be a determinant factor for elevation of blood pressure, both for obese and nonobese children and adults ${ }^{3,4}$. In addition, the presence of obesity is related to a 2.5 higher risk of arterial hypertension, mainly in patients with central body fat distribution ${ }^{5}$. Several hypotheses exist for the pathophysiology of arterial hypertension in this obese population. The first and more accepted hypothesis proposes that hyperinsulinemia secondary to insulin resistance existing in these patients leads to greater sympathetic activity and to renal sodium retention, which would account for the increase in pressure levels ${ }^{6-8}$. The second hypothesis associates the arterial hypertension existing in these patients with the mechanical compression of renal parenchyma by visceral fat. This leads to hyperactivation of the renin-angiotensinaldosterone system (RAAS), higher sodium reabsorption, and a subsequent elevation in blood pressure by a mechanism independent from insulinemia ${ }^{9,10}$.

Even though we have not reached a consensus about the causes of arterial hypertension in the obese, several clinical studies confirm the importance of weight loss to better control blood pressure levels ${ }^{11,12}$.

The great challenge has been to find effective clinical treatments, which do not impair blood pressure control, to induce weight loss in hypertensive patients. Of the several treatments available for weight control, we can count on appetite suppressing drugs, which comprise a generic class of drugs derived from amphetamines that act through adrenergic receptors, and, therefore, may aggravate hypertension. More recently, other options include orlistat that inhibits gastrointestinal fat absorption, and sibutramine, an appetite suppressant that blocks serotonin, dopamine, and noradrenaline reuptake ${ }^{13}$.

The use of sibutramine is associated with an increase in satiety scores and a lack of decline in 24-hour energy 
expenditure ${ }^{14,15}$, which make sibutramine efficient in inducing weight loss. Several studies show an adequate tolerability profile for the drug; however, aspects referring to hypertensive patients are still inconclusive, and the presence of higher adrenergic activity may interfere with the benefits resulting from weight loss.

We carried out a prospective, double blind study for 6 months to assess the effects of the use of sibutramine or placebo on blood pressure levels, left ventricular mass and evolution of the antihypertensive therapy in obese and hypertensive patients. In addition, we assessed drug tolerability through the analysis of the frequency of clinical and laboratory adverse effects.

\section{Methods}

We selected 109 obese patients $\left(30 \mathrm{~kg} / \mathrm{m}^{2}<\mathrm{BMI}\right.$ $<50 \mathrm{~kg} / \mathrm{m}^{2}$ ) who were being followed up at the UNIFESP in the outpatient clinic for obesity. These patients had arterial hypertension $(95 \mathrm{mmHg}<\mathrm{DBP}<110 \mathrm{mmHg}$; or DBP $<95 \mathrm{~mm}$ $\mathrm{Hg}$ if on medication) and a preferentially central body fat distribution (waist/hip ratio above 0.85 for females and 0.95 for males). The following patients were excluded from the study: diabetic patients undergoing any treatment for weight loss; patients using medications, such as corticosteroids or tricyclic derivatives; and patients with endocrine diseases that could interfere with body weight. After randomization, the patients were advised to follow a diet of 1,200 and 1,500 calories (females and males, respectively) and received placebo or $10 \mathrm{mg}$ of sibutramine for 6 months. These patients were followed up with monthly visits for a complete physical examination (weight, height, blood pressure, heart rate, waist and hip circumferences), assessment of adverse effects, and necessary adjustments in the concomitant antihypertensive medication. During the study, the following patients were excluded: patients with changes in the hepatic enzymes above twice the normal limit; patients whose diastolic blood pressure levels exceeded $110 \mathrm{mmHg}$, even under treatment; patients who started to use corticosteroids, or who interrupted the prescribed medication for more than 1 week. Blood samples were withdrawn at the $1^{\text {st }}, 12^{\text {th }}$, and $24^{\text {th }}$ weeks to measure alkaline phosphatase (AKP), gammaglutamyl transpeptidase (GGT), and glutamic-oxaloacetic (GOT) and glutamic-pyruvic (GPT) transaminases (method: spectrophotometry). At the beginning of the study, the patients underwent the following tests: total cholesterol, HDL-cholesterol, and triglycerides (method: colorimetric enzymatic), and the oral glucose tolerance test, with glucose measurements (method: oxidase glucose) during fasting and every 30 minutes up to 2 hours after glucose overload. At the beginning and at the end of the study, the cardiac mass was measured by Doppler echocardiography (Escote Biomédica; Florence, Italy), and mass index was calculated considering the patient's height, according to Levy and Lauer et al ${ }^{16-18}$, and was used to characterize ventricular hypertrophy in this obese population. A 24-hour blood pressure profile was obtained using 24-hour ambulatory blood
Sibutramine on the obesity in patients with hypertension

pressure monitoring (Spacelabs 90202 Equipment, Redmond, WA). The percentage drop ( $\% \Delta$ ) in mean systolic blood pressure (MSBP) during sleep was calculated using the formula: DN = MSBP (wakefulness) - MSBP (sleep) $\mathrm{x}$ 100/MSBP (wakefulness).

Statistical analysis: we used the Sigma Stat software (SPSS Industry). Data were expressed as mean \pm standard deviation. The Student $t$ test for dependent and independent variables was used for intra- and intergroup comparison, respectively. The frequencies of adverse effects, causes of exclusion from the study, and changes in the antihypertensive medication between the groups were compared using the chisquare test. It was considered significant a p value $<0.05$.

\section{Results}

Twenty-three patients (13/10, placebo/sibutramine) did not complete the study due to different causes: biochemical alterations in the blood $(1 / 1 ; \mathrm{ns})$, poor treatment compliance $(8 / 7 ; \mathrm{ns})$, hypertensive crisis due to interruption of the antihypertensive treatment $(1 / 1 ; \mathrm{ns})$; inappropriate use of corticosteroids $(2 / 1 ; n s)$; and pyelonephritis $(1 / 0$; ns). At the end of the study, we assessed 43 patients in each group, accounting for $88 \%$ and $83 \%$ of female patients in the placebo and sibutramine groups, respectively. Except for age (50.6 \pm 8.1 in the placebo group versus $46.4 \pm 8.2$ in the sibutramine group, $\mathrm{p}<0.01$ ), no significant difference was observed in the initial clinical characteristics between the 2 groups (tab. I). The prevalence of glucose intolerance, total cholesterol $>200 \mathrm{mg} / \mathrm{dL}$, and triglycerides $>180 \mathrm{mg} / \mathrm{dL}$ in the study population was, respectively, $34 \%, 52 \%$, and $29 \%$.

Considering only the patients who completed the stu$\mathrm{dy}$, a weight loss of $6.8 \pm 2.3 \mathrm{~kg}(6.7 \%)$ in the sibutramine group and of $2.4 \pm 4.2 \mathrm{~kg}(2.5 \%)$ in the placebo group $(\mathrm{p}<0.001)$ occurred. Weight loss greater than 5\% occurred in $27(62.8 \%)$ and 10 (23.2\%) patients of the sibutramine and placebo grou$\mathrm{ps}$, respectively $(\mathrm{p}<0.001)$. Table I shows that a significant reduction in the waist/hip ratio occurred in the sibutramine group, indicating an improvement in body fat distribution.

Systolic and diastolic blood pressure measured at the medical office, the mean systolic (MSBP) and diastolic (MDBP) blood pressures during ambulatory blood pressure monitoring, the percentage drop $(\% \mathrm{D})$ in mean systolic blood pressure during sleep, and mean heart rate during 24 hours did not significantly change in either group (tab. I). Heart rate measured at the office showed a significant increase in the sibutramine group ( $78.3 \pm 7.3$ versus $82 \pm 7.9$ $\mathrm{bpm} ; \mathrm{p}=0.02)$, but not in the placebo group $(76.3 \pm 9.6$ versus $75.68 \pm 8.8 \mathrm{bpm}$; ns).

The characteristics of the initial antihypertensive treatment and its changes throughout the study are detailed in table II. As can be seen, the proportion of untreated patients and those treated with 1 or more agents did not differ in the 2 groups. The proportions of patients using different classes of antihypertensive agents also did not differ in the 2 groups. Only $18.6 \%$ of the patients in both groups were not using antihypertensive medication at the beginning of 
Table I-Clinical and laboratory characteristics, ambulatory blood pressure monitoring values, and initial and final echocardiographic findings of the placebo and sibutramine groups (mean \pm SD))

\begin{tabular}{|c|c|c|c|c|}
\hline \multirow{2}{*}{$\begin{array}{l}\text { Physical } \\
\text { examination }\end{array}$} & \multicolumn{2}{|c|}{ Placebo $(n=43)$} & \multicolumn{2}{|c|}{ Sibutramine $(n=43)$} \\
\hline & Basal & Final & Basal & Final \\
\hline $\mathrm{BMI}\left(\mathrm{kg} / \mathrm{m}^{2}\right)$ & $38.8 \pm 5.4$ & $37.7 \pm 5.5$ & $40.1 \pm 5.5$ & $37.5 \pm 5.6^{*}$ \\
\hline WHR & $0.97 \pm 0.08$ & $0.96 \pm 0.08$ & $0.97 \pm 0.09$ & $0.94 \pm 0.07 *$ \\
\hline $\mathrm{SBP}(\mathrm{mm} \mathrm{Hg})$ & $149.5 \pm 15.0$ & $148.9 \pm 21.7$ & $150.2 \pm 18.15$ & $145.6 \pm 15.1$ \\
\hline $\mathrm{DBP}(\mathrm{mm} \mathrm{Hg})$ & $94.16 \pm 11.52$ & $92.1 \pm 13.5$ & $91.0 \pm 12.3$ & $92 \pm 13.3$ \\
\hline HR (bpm) & $76.3 \pm 9.6$ & $75.68 \pm 8.8$ & $78.3 \pm 7.3$ & $82 \pm 7.9^{*}$ \\
\hline \multicolumn{5}{|l|}{ Biochemistry } \\
\hline $\mathrm{FA}(\mathrm{U} / \mathrm{l})$ & $81.4 \pm 29.6$ & $99.4 \pm 47.1 *$ & $83.9 \pm 28.7$ & $104.2 \pm 38.5^{*}$ \\
\hline GGT (U/l) & $23.9 \pm 15.8$ & $25.2 \pm 16.1$ & $26.2 \pm 12.8$ & $30.7 \pm 21.4$ \\
\hline TGO (U/l) & $21.5 \pm 9.0$ & $21.4 \pm 10.4$ & $20.2 \pm 5.7$ & $21.3 \pm 12.9$ \\
\hline TGP (U/l) & $23.3 \pm 14.8$ & $22.2 \pm 13.8$ & $24.3 \pm 12.4$ & $24.1 \pm 16.7$ \\
\hline \multicolumn{5}{|c|}{$\begin{array}{l}\text { Ambulatory blood pressure monitoring } \\
\text { day MSBP }\end{array}$} \\
\hline $\begin{array}{l}(\mathrm{mmHg}) \\
\text { day MDBP }\end{array}$ & $131.4 \pm 13.5$ & $130.6 \pm 14.9$ & $137.6 \pm 14.5$ & $135.7 \pm 11.1$ \\
\hline $\begin{array}{l}\text { (mmHg) } \\
\text { nocturnal MSBP }\end{array}$ & $82.9 \pm 9.7$ & $81.2 \pm 9.3$ & $84.6 \pm 9.08$ & $84 \pm 8.16$ \\
\hline $\begin{array}{l}(\mathrm{mmHg}) \\
\text { nocturnal MDBI }\end{array}$ & $\begin{array}{l}120.8 \pm 12.6 \\
P\end{array}$ & $123 \pm 15.5$ & $124.5 \pm 16.2$ & $127.43 \pm 13.1$ \\
\hline$(\mathrm{mmHg})$ & $71.7 \pm 9.5$ & $72.4 \pm 9.2$ & $71.4 \pm 9.7$ & $74.84 \pm 9.38$ \\
\hline$\% \Delta(\%)$ & $7.9 \pm 5.5$ & $7.44 \pm 5.2$ & $9.3 \pm 7.8$ & $7.9 \pm 6.05$ \\
\hline 24h-HC (bpm) & $97.2 \pm 9.9$ & $97.8 \pm 10.8$ & $100.1 \pm 10.05$ & $101.9 \pm 8.4$ \\
\hline ECO & & & & \\
\hline $\operatorname{LVM}(\mathrm{g})$ & $176 \pm 38.2$ & $164.8 \pm 45.0$ & $168.5 \pm 51.4$ & $154.6 \pm 50.8^{*}$ \\
\hline LVM/HEI (g/m) & $110.1 \pm 22.4$ & $103.9 \pm 27.9$ & $105 \pm 29.3$ & $96.6 \pm 28.6 *$ \\
\hline
\end{tabular}

${ }^{*} \mathrm{p}<0.05$ versus basal; BMI- body mass index; WHR- waist/hip ratio; SBPsystolic blood pressure; DBP- diastolic blood pressure; HR- heart rate; AKPalkaline phosphatase; GGT- gamma-glutamyl transpeptidase; GOT- glutamicoxaloacetic transaminase; GPT- glutamic-pyruvic transaminase; MSBP- mean systolic blood pressure; MDBP- mean diastolic blood pressure; \%D- percentage drop in systolic blood pressure during sleep; 24h-HR- heart rate in 24 hours; LVM- left ventricular mass; LVM/HEI- left ventricular mass corrected to height.

\begin{tabular}{|c|c|c|c|}
\hline \multicolumn{4}{|c|}{$\begin{array}{l}\text { Table II - Characteristics of the antihypertensive treatment in each } \\
\text { group. Number of agents, qualitative distribution of the antihyperten- } \\
\text { sive drugs in the } 2 \text { groups, and evolution of the treatment after } 6 \text { months } \\
\text { (placebo and sibutramine) }\end{array}$} \\
\hline & $\begin{array}{c}\text { Placebo } \\
(n=43)\end{array}$ & $\begin{array}{l}\text { Sibutramine } \\
\qquad(\mathrm{n}=43)\end{array}$ & \\
\hline \multicolumn{4}{|c|}{ Initial number of antihypertensive agents (n) (\%) } \\
\hline None & $8(18.6 \%)$ & $8(18.6 \%)$ & NS \\
\hline 1 agent & $11(25.6 \%)$ & $22(51.1 \%)$ & NS \\
\hline 2 agents & $16(37.2 \%)$ & $10(23.2 \%)$ & NS \\
\hline 3 or more agents & $8(18.6 \%)$ & $3(6.9 \%)$ & NS \\
\hline \multicolumn{4}{|c|}{ Classes of the initial antihypertensive agents (n) (\%) } \\
\hline Diuretics & $26(60.5 \%)$ & $22(51.1 \%)$ & NS \\
\hline Beta-blockers & $7(16.2 \%)$ & $6(13.9 \%)$ & NS \\
\hline ACE inhibitors & $18(41.8 \%)$ & $13(30.2 \%)$ & NS \\
\hline Calcium blockers & $9(20.9 \%)$ & $6(13.9 \%)$ & NS \\
\hline Others & $3(6.9 \%)$ & $5(11.6 \%)$ & NS \\
\hline \multicolumn{4}{|c|}{ Variation in the medication (n) (\%) } \\
\hline Reduction & $12(27.9 \%)$ & $7(16.2 \%)$ & $\mathrm{p}=0.28(\mathrm{NS})$ \\
\hline Maintenance & $17(39.5 \%)$ & $23(53.5 \%)$ & $\mathrm{p}=0.29(\mathrm{NS})$ \\
\hline Increase & $14(32.5 \%)$ & $13(30.2 \%)$ & $\mathrm{p}=1.00(\mathrm{NS})$ \\
\hline
\end{tabular}

the study. After 6 months of treatment, $27.9 \%$ and $16.2 \%$ of the patients $(\mathrm{p}=0.28)$ in the placebo and sibutramine groups, respectively, had evolved with a reduction in the number or dosage of the antihypertensive agents initially used. Maintenance of the medication was observed in $39.5 \%$ and $53.5 \%$ of the patients $(\mathrm{p}=0.29)$ in the placebo and sibutramine groups, respectively, while $32.5 \%$ and $30.2 \%$ of the patients, respectively, required an increase in the number or dosage of the antihypertensive agents used $(\mathrm{p}=1.0)$.

Considering the patients in the 2 groups undergoing echocardiography, the prevalence of ventricular hypertrophy (LVM/HEI $>110 \mathrm{~g} / \mathrm{m}$ ) was $31 / 80(38.7 \%)$ at the beginning of the study, and 26/81 (32\%) at the end of the study ( $\mathrm{p}=0.36$; ns). Left ventricular mass and left ventricular mass index corrected for height showed a significant reduction after treatment in the sibutramine group ( $\mathrm{p}=0.002)$, but not in the placebo group (tab. I and fig. 1). In the sibutramine group, a tendency towards correlation between the percentage of weight loss and the reduction in left ventricular mass index was observed $(\mathrm{r}=0.27 ; \mathrm{p}=0.08)$. Considering only those patients who achieved weight loss above $5 \%$ and underwent the same analysis, a significant reduction in left ventricular mass index corrected for height was observed in the sibutramine group $(106.9 \pm 31.8$ versus $99.8 \pm 29.7 \mathrm{~g} / \mathrm{m} ; \mathrm{p}=0.04)$. The prevalence of hypertrophy did not change in the 2 groups.

The most frequent adverse effects were as follows: dry mouth, insomnia, nervousness, cephalea, constipation, and arthralgia. None of these adverse effects required interruption of the medication. Only dry mouth $(37.2 \%$ versus $9.3 \% ; \mathrm{p}<0.005)$ and arthralgia $(16.2 \%$ versus $2.3 \%$; $\mathrm{p}=0.03$ ) were more frequent in the sibutramine group.

Biochemical alterations in alkaline phosphatase (values $>200 \mathrm{IU} / \mathrm{L}$ ) caused the exclusion of 1 patient in each group. Biochemical fluctuations below that level were followed up, and the frequency of values above $100 \mathrm{IU} / \mathrm{L}$ prior to and after the treatment was compared in both groups. Even though the frequency of alkaline phosphatase values above $100 \mathrm{IU} / \mathrm{L}$ was significantly higher at the end of the study in the sibutramine group $(44.2 \%$ versus $18.6 \%$; $\mathrm{p}=0.02)$, the mean values of alkaline phosphatase in these patients did not differ in the 2 groups ( $137.3 \pm 29.5$ versus $147.0 \pm 57.7$, sibutramine and placebo groups, respectively; $\mathrm{p}=0.5$ ). In addition, considering all patients who completed the study, statistically significant increases of similar magnitude in alkaline phosphatase values occurred in the 2 groups (tab. I).

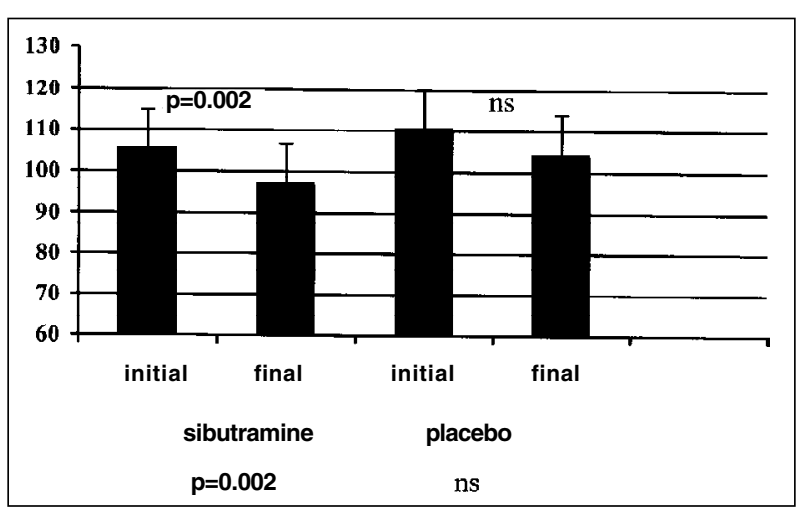

Fig. 1 - Initial and final MVE/ALT in the 2 groups (sibutramine and placebo) mean \pm SD. 


\section{Discussion}

In our trial, the treatment of obese hypertensive patients with sibutramine was more effective in inducing weight loss than that with placebo. In a 6-month period, this weight loss reached $6.7 \%$ in the sibutramine group and $2.5 \%$ in the placebo group, which is a value similar to those obtained in other studies ${ }^{19,20}$.

Part of the effects of sibutramine is due to the inhibition of noradrenaline reuptake with the resulting maintenance of adrenergic tonus in these patients, which can be beneficial for avoiding the drop in energy expenditure that follows weight loss according to the studies by Hansen et al ${ }^{14}$ and Seagle et al ${ }^{15}$. This effect, however, could result in an elevation in blood pressure and a reduction in the antihypertensive benefits of weight loss. In fact, previous studies in normotensive patients reported elevations in heart rate and blood pressure associated with the use of sibutramine ${ }^{15}$.

In our study, even though an increase in heart rate measured at the medical office was observed in the sibutramine group, the same was not observed on ambulatory blood pressure monitoring. No alteration in blood pressure levels occurred, either at the medical office or on ambulatory blood pressure monitoring. Concomitant adjustments of the antihypertensive medication were performed aiming at avoiding fluctuations in blood pressure. We observed that increases in the dosage or number of antihypertensive drugs were performed in the same proportion in both groups, suggesting that the increase in the sympathetic activity is not of a magnitude sufficient to interfere with blood pressure control in treated hypertensive patients. On the other hand, as the weight loss was significantly greater in the sibutramine group, and the magnitude of the reduction in the antihypertensive therapy was similar in both groups, loss of the antihypertensive benefits due to weight loss was observed.

In the obese population studied, the diuretic, used alone or in combination, was the most frequently used drug to treat hypertension followed by angiotensin-converting enzyme inhibitors as shown in table II. Due to the constant volume overload that exists in hypertensive obese patients ${ }^{12}$, the association of diuretic drugs is frequently necessary for adequate blood pressure control.

Even though no reduction in the prevalence of myocardial hypertrophy was observed in the period studied, a significant reduction occurred in ventricular mass and in its index corrected for height in the sibutramine group, but not in the placebo group. This occurred despite the lack of variations in the different parameters of ambulatory blood pressure monitoring in the 2 groups, revealing the cardio- vascular benefits of weight loss not related to blood pressure levels. Myocardial hypertrophy in the obese hypertensive patient is known to result from the 2 following pathophysiological factors: volume overload determined by weight and the increase in peripheral vascular resistance. Therefore, after adjustments for height, obese normotensive patients show ventricular hypertrophy of a magnitude similar to that seen in nonobese hypertensive patients, while obese hypertensive patients show a higher degree of hypertrophy as compared with that of the other groups ${ }^{21}$. Our results suggest that the reduction in ventricular mass occurred preferentially due to a reduction in volume overload secondary to weight loss, because the blood pressure levels remained stable. Therefore, weight loss per se, even not associated with a drop in blood pressure, was related to a cardiovascular benefit in this group of patients.

An increase in the levels of alkaline phosphatase, but not in the other hepatic enzymes, was observed in our patients during the study. At the end of the treatment, the 2 groups showed statistically significant increases in alkaline phosphatase, but only the sibutramine group experienced an increased frequency in values above $100 \mathrm{IU} / \mathrm{L}$. Studies assessing degree 3 obese patients $\left(\mathrm{BMI}>40 \mathrm{~kg} / \mathrm{m}^{2}\right.$ ) with hepatic steatosis showed that weight loss, despite its association with a reduction in hepatic steatosis, may have resulted in a moderate hepatic inflammatory lesion. This lesion could be caused by the rapid mobilization of fatty acids and cytokines in the adipose tissue, especially in visceral adipose tissue ${ }^{22,23}$.

In conclusion, sibutramine proved to be efficient in inducing weight loss, leading to a reduction in left ventricular mass in obese and hypertensive patients. No significant interference was observed in blood pressure levels, allowing us to state that in obese and hypertensive patients, in whom clinical supervision and adjustments in the antihypertensive therapy are possible, the use of sibutramine poses no additional risks. The most frequent adverse effects associated with the use of sibutramine in this population were dry mouth and arthralgia, and a higher frequency of insomnia or irritability, as suggested in other studies, was not found. The alterations reported in alkaline phosphatase cannot be attributed to the use of sibutramine and may be associated with the mobilization of visceral adipose tissue; larger studies, however, are required to confirm this hypothesis.

\section{Acknowledgments}

We thank the Abbott Laboratories of Brazil. 


\section{References}

1. Monteiro CA, Conde WL. A tendência secular da obesidade segundo extratos sociais: nordeste e sudeste, 1975-1989-1997. Arq Bras Endocrin Metab 1999; 43; 186-94

2. World health Organization. Obesity: preventing and managing the global epidemic. Report of a WHO consultation on Obesity: Geneva, 1998.

3. He Q, Ding ZY, Fong DY. Kalberg J. Blood pressure is associated with body mass index in both normal and obese children. Hypertension 2000; 36: 165-70.

4. Masuo K, Mikami H, Ogihara T, Tuck ML. Weight gain- induced blood pressure elevation. Hypertension 2000; 35: 1135-40.

5. Lurbe E, Alvarez V, Laio Y, et al. the impact of obesity and body fat distribution on ambulatory blood pressure in children and adolescents. Am J Hypertens 1998; 11(4pt1): 418-24

6. Berne C. Insulin resistance in hypertension: a relationship with consequences? J Intern Med 1991; 229(Suppl. 2): 65-73.

7. Reaven GM, Lithell H, Landsberg L. Hypertension and associated metabolic abnormalities - the role of insulin resistance and the sympathoadrenal system. N Engl J Med 1996; 334: 374-81.

8. Moan A, Nordby G, Rostrup M, et al. Insulin sensitivity, sympathetic activity, and cardiovascular reactivity in young men. Am J Hypertension 1995; 8: 268-73.

9. Hall JE, Zappe D, Kassab S. Mechanisms of obesity induced hypertension. N Physiol Science 1996; 11: 255-61.

10. Hall JE. Renal and cardiovascular mechanisms of hypertension in obesity. Hypertension Dallas 1994; 23: 381-94.

11. Sjostrom CD, Lissner L, Wedel H, Sjostrom L. Reduction in incidence in diabetes, hypertension and lipid disturbances after intentional weight loss induced by bariatric surgery: the SOS interventional study. Obes Res 1999; 7: 477-84.

12. Benotti PN, Forse RA, Blackburn G, Benotti JR, Bistraim B. Heart disease and hypertension: the benefits of weight reduction. Am J Clin Nutr 1992; 55(2 suppl): 586s-90s.
13. Grundlah C, Heal DJ, Auerbach SB. In vivo criteria to differentiate monoamine reuptake inhibitors from releasing agents: sibutramina is a reuptake inhibitor. J Pharmacol Exp Ther 1997; 283: 581-91.

14. Hansen DL, Toubro S, Stock MJ, Macdonald IA, Astrup A. The effect of sibutramine on energy expenditure and appetite during chronic treatment without dietary restriction. Int J Obes 1999: 23; 1016-24.

15. Seagle HM, Bessesen DH, Hill JO. Effects of sibutramina on resting metabolic rate and weight loss in overweight women. Obes Res 1998; 6: 115-21.

16. Levy D, Savage DD. Echocardiographic criteria for left ventricular hypertrophy: the Framingham Heart Study. Am J Cardiol 1987; 59: 960-5.

17. Levy D, Anderson KM. Echocardiographically detect left ventricular hypertrophy: prevalence and risk factors. The Framingham Heart Study. Ann Intern Med 1988; 108: 7-13.

18. Lauer MS, Anderson KM, Kannel WB. The impact of obesity on left ventricular mass and geometry. JAMA 1991; 266: 231-6.

19. Finer $\mathrm{N}$ and Storm Study Group. Sibutramine trial of obesity reduction and maintenance: efficacy during the six month run-in phase. Int J Obes Relat Metab Disord 1998; 22(suppl 3): s272.

20. Apfelbaum M, Vague P,Ziegler O, Hanotin C, Thomas F, LeuteneggerE. Long term maintenance of weight loss after very low calorie diet: a randomized blinded trial of the efficacy and tolerability of sibutramina. Am J Med 1999; 106: 179-84.

21. Ribeiro Filho FF, Rosa EC, Faria AN, et al. Obesidade, hipertensão arterial e suas influências sobre a massa e função do ventrículo esquerdo. Arq Bras Endocrin Metab 2000; 44: 64-71.

22. Luyckx FH, Lefebvre PJ, Scheen AJ. Non alcoholic steatohepatitis: association with obesity and insulin resistance, and influence of weight loss. Diabetes 2000; 26: 98-106

23. Luyckx FH, Desaive C, Thiry A, et al. Liver abnormalities in severely obese subjects: effect of drastic weight loss after gastroplasty. Int J Obes Relat Metab Disord 1998; 22: 222-6. 